\title{
IDENTIDADES JUVENIS E EXPERIÊNCIA ESCOLAR NO ENSINO MÉDIO
}

\author{
E. O. SOUZA ${ }^{1}$, R. REIS ${ }^{2}$ e J. M. C. T. SANTOS ${ }^{3 *}$ \\ Universidade do Estado do Rio Grande do Norte - UERN \\ Universidade Federal das Alagoas - UFAL \\ maccolle@hotmail.com*
}

Artigo submetido em julho/2015 e aceito em julho/2015

DOI: $10.15628 /$ holos.2015.3189

\section{RESUMO}

O presente artigo trata das relações entre identidades juvenis e a experiência escolar das juventudes do Ensino Médio a partir de relatos de jovens sobre as suas representações em relação a experiência escolar e a vivência das diversas condições juvenis. Assim, analisamos, primeiro, em que sentido as experiências da escola se relacionam com as construções identitárias desses jovens, e, segundo, tendo essa questão como foco, problematizar as relações entre a experiência escolar e a construção identitária vivenciada dentro do cenário de dificuldades que apresenta a escola pública de Ensino Médio em Alagoas.

PALAVRAS-CHAVE: Identidades, juventudes, escola, ensino médio.

\section{IDENTITIES YOUTH AND SCHOOL EXPERIENCE IN HIGH SCHOOL}

\section{ABSTRACT}

This article deals with the relationships between youth identities and the school experience of youths of high school youth from reports on their representations in relation to school experience and the experience of various youth conditions. Thus, we analyzed first, in what sense the school experiences relate to the identity constructions of these young people, and second, having this issue as focus, discuss the relationship between the school experience and identity construction difficulties experienced within the scenario that presents the public high school education in Alagoas.

KEYWORDS: Identities, youth, school, high school. 


\section{APRESENTAÇÃO}

Compartilhamos com Pais (2003) o pressuposto de que é preciso adentrar os contextos vivenciais, cotidianos dos jovens para compreender o sentimento de pertencimento e como compartilham e representam símbolos e valores. Compreendemos que as identidades são construções socioculturais, provisórias, negociadas, reinventadas e constituídas de modo relacional com o outro, numa relação de alteridade (ZALUAR, 2003), em determinado contexto histórico, cultural, político e econômico.

As juventudes, nessa perspectiva, estão inscritas em determinadas relações de classes, de gênero, de etnia, em diversos espaços em que transitam e se deparam com questões de consumo, de religião, de geração e com as implicações das diferentes inserções no mundo do trabalho. Para a grande maioria, de algum modo, há ainda uma estreita relação com a educação escolar. Portanto, a escola, embora não seja o único, é um importante espaço de atuação no qual as identidades juvenis são negociadas e reinventadas.

Com tudo isso, podemos afirmar que as juventudes são múltiplas e compartilham códigos, símbolos, significados e sentidos dos sistemas culturais nos quais estão inseridas. Essa compreensão traz à tona questionamentos em relação a definições seguras e estáveis dos modos de compreender identidade e juventude. Com tal embasamento, o presente artigo trata das possíveis relações entre identidades juvenis e a experiência escolar das juventudes do Ensino Médio a partir de relatos de jovens sobre as suas representações em relação a experiência escolar e a vivência das diversas condições juvenis (ABRAMO, 2005). Buscamos, então, analisar, primeiro, em que sentido as experiências da escola se relacionam com as construções identitárias desses jovens, e, segundo, tendo essa questão como foco, problematizar as relações entre a experiência escolar e a construção identitária vivenciada dentro do cenário de dificuldades que apresenta a escola pública de Ensino Médio em Alagoas.

\section{CONCEITUANDO IDENTIDADES E CULTURAS JUVENIS}

Definir um conceito atual de identidade é algo extremamente complexo, sendo impossível fazer afirmações conclusivas, uma vez que os debates e estudos sociológicos referentes a esse assunto são bastante variados. Tendo como referência uma noção de sujeito pós-moderno (HALL, 2006, p. 13), percebemos que, uma vez que o mundo apresenta-se de forma fragmentada, o sujeito não é composto de uma, mas de várias identidades, fruto de um processo que se tornou "provisório, variável e problemático" (ibidem). Para Hall, o processo de identificação produz um sujeito que "não tem uma identidade fixa, essencial ou permanente", mas uma identidade que se transforma continuamente reagindo às intervenções dos sistemas culturais nos quais o sujeito está inserido, assumindo "identidades diferentes em momentos diferentes", são as chamadas "identidades possíveis", com cada umas das quais poderíamos nos identificar - ao menos temporariamente (ibidem).

Atualmente, a disseminação do uso da Internet, a velocidade e a variedade dos meios de informação, rompem as barreiras físicas e contribuem para o fácil acesso a diversas realidades 
culturais, isso facilita uma transformação na constituição das identidades, fortalecendo a afirmação de que as identidades modernas encontram-se "descentradas, deslocadas ou fragmentadas" (ibidem, p. 8). Isso pode gerar certo distanciamento em relação ao que se refere às raízes e tradições culturais - em relação à história, às artes locais, ao folclore. Neste aspecto, segundo Hall, as velhas identidades, que por tanto tempo estabilizaram o mundo social, estão em declínio, fazendo surgir novas identidades (identificações provisórias) e fragmentando o indivíduo moderno, antes visto como um sujeito unificado. O autor utiliza o termo "crise de identidade" que está inserido num processo mais amplo de mudança, ligado ao deslocamento das estruturas e processos centrais das sociedades modernas que vêm abalando os contextos que davam aos indivíduos uma (ilusória) referência estável no mundo social.

Sobre esse tema, Dubar (2009) faz uma análise da questão da subjetividade na sociologia atual, ajudando na superação da proposição de permanência embutida no conceito de identidade, recorrendo a teorias sociológicas que sustentam a hipótese de que a definição de indivíduo e de seu lugar no processo social muda progressivamente no decorrer da história, mais perceptível ao longo dos últimos trinta anos, a partir da mutação da configuração das formas de percepção identitárias. Para ele, as formas identitárias configuradas nos períodos anteriores perderam sua legitimidade. É nesse sentido de desestabilização do que se tinha anteriormente como formas de identidades, que se pode falar de uma "crise das identidades", uma vez que a mudança de normas e de modelos gerada por essa crise causa desestabilização das referências anteriores, interferindo na subjetivação dos indivíduos.

As repercussões de tais mudanças sobre o processo de socialização e de construção de vínculos sociais são notáveis: ao ameaçarem a estabilidade dos dispositivos de integração social, as mudanças visíveis na atualidade incidem diretamente sobre as relações entre o indivíduo e o social e, portanto, sobre o processo de construção das identidades pessoais. Não mais supostamente assegurado pelas instituições tradicionais, este processo passa a ser construído pelos próprios indivíduos no decurso de suas trajetórias de vida.

As formas identitárias seriam sistemas de designação, historicamente variáveis, que, segundo Dubar (2009), religariam as identificações por e para o "Outro" - atribuídas por terceiros em um espaço social e contexto histórico específico - e as identificações por e para "Si" - marcadas pela temporalidade e pelos percursos biográficos. É no entremeio destas duas formas identitárias que se forjam as crises existenciais e as crises de identidade pessoal tão evidentes na atualidade, crises que envolvem a definição de si, tanto quanto o reconhecimento atribuído pelos outros.

Permeando essa construção das identidades, para si e para os outros, encontra-se a representação. Baseando-se nos estudos culturais, Stuart Hall explica que a representação se constitui através do uso que fazemos das coisas, dos significados que damos a elas, do que dizemos, pensamos e sentimos. Seu significado surge não das coisas em si, mas a partir dos jogos da linguagem e dos sistemas de classificação nos quais as coisas são inseridas. O que consideramos fatos naturais são, portanto, também fenômenos discursivos (HALL, 1997), ou seja, a linguagem está no centro da expressão da representação, quando comunicamos expomos ao mundo nossos significados. Hall (1997), assim, afirma que nossas subjetividades são produzidas de modo discursivo e dialógico, por isso, quando há a intervenção da cultura, é cada vez mais difícil definir a diferença entre o que é "interior" e "exterior", entre o que é social e o que é psíquico. Segundo 
ele, devemos pensar as identidades sociais como construídas no interior da representação, através da cultura, não fora dela. Elas são o resultado de um processo de identificação que permite que nos posicionemos no interior das definições que os discursos culturais (exteriores) fornecem ou que nos subjetivemos (dentro deles) Sendo assim, os significados culturais não estão somente no nível mental, na imaginação, mas têm efeitos reais e regulam as práticas sociais. $O$ reconhecimento dos significados, a sensação de pertencimento, é parte da consciência de nossa própria identidade.

Assim como as identidades, as culturas também precisam ser pensadas no plural, bem como o conceito de juventudes. (NOVAES apud OLIVEIRA et alii, 2006), uma vez que os jovens, individualmente ou inseridos nos grupos juvenis, têm vivências diferentes, em condições também diferenciadas, muitas vezes inseridos em grupos sociais que se organizam e explicam suas formas de estar no mundo construindo identidades.

Abordar a relação entre cultura e juventude exige, então, perceber como os indivíduos vivem essa juventude: as vulnerabilidades e potencialidades contidas em suas condições de vida e a pluralidade de expressões culturais que emergem da experiência dos grupos juvenis. Com efeito, é impossível refletir a respeito da construção das identidades juvenis sem considerar a sua relação com a noção de "culturas juvenis".

Pais (2003) afirma que se queremos decifrar os enigmas dos paradoxos da juventude precisamos refletir sobre os significados compartilhados fazendo três questionamentos: "1. Se os jovens compartilham os mesmos significados; 2. Se, no caso de compartilharem os mesmos significados, o fazem de forma semelhante; 3. A razão por que compartilham ou não, de forma semelhante ou distinta, determinados significados." (PAIS, 2003, p. 70). São essas variações de compatibilidade de valores e símbolos que dão origem às variedades de juventudes, exigindo do pesquisador sensibilidade e critérios para observar nas falas de cada jovem as nuances que os diferencia e impossibilita que os vejamos como a categoria única e homogênea.

Somente observando os contextos onde os jovens vivem cotidianamente é que podemos compreender seus sentimentos de pertencimento, como constroem seus símbolos e valores, expressos em seus modos de vestir, em seus gestos e em tudo o que de alguma forma produz significados de si.

Desse modo, "o mundo da cultura aparece como um espaço privilegiado de práticas, representações, símbolos e rituais, no qual os jovens buscam demarcar uma identidade juvenil (DAYRELL, 2007, p. 1110). Nesse aspecto, a sociabilidade aparece aliada às expressões culturais como dimensões da condição juvenil. Para compreender os jovens é preciso levar em conta a dimensão da 'experiência vivida', que permite aprender a história como fruto da ação dos sujeitos. "Estes experimentam suas situações e relações produtivas como necessidades, interesses e antagonismos e elaboram essa experiência em sua consciência e cultura, agindo conforme a situação determinada." (DAYRELL, 1996, p. 140). Diante dos referidos conceitos, podemos refletir sobre qual a relação da escola com as identidades culturais dos jovens estudantes, atentando para a participação da escola na construção da identidade dos jovens alunos.

Segundo Dayrell, "os alunos chegam à escola marcados pela diversidade, reflexo dos desenvolvimentos cognitivo afetivo e social, evidentemente desiguais, em virtude da quantidade e qualidade de suas experiências e relações sociais, prévias e paralelas à escola" (ibidem). O que 
cada um deles é, ao chegar à escola, é fruto de um conjunto de experiências sociais vivenciadas em diferentes espaços sociais. Para o autor, um dos desafios do Ensino Médio é desvendar os sentidos atribuídos pelos jovens à educação. O que poderia apontar importantes caminhos para a construção de um projeto político pedagógico para que as escolas correspondessem às demandas da juventude (DAYRELL, 2007, p. 5).

A partir das considerações anteriores analisamos as falas dos jovens participantes de nossa pesquisa com foco em suas impressões e anseios sobre a experiência escolar. Os jovens que participaram dessa pesquisa constroem suas identidades no entrecruzamento e imbricação de seus papéis sociais de "ser jovem" e de "ser estudante no ensino médio", na sua "relação com os outros" na escola e em outras realidades sociais nas quais convivem.

\section{EXPRESSÕES DE IDENTIDADES JUVENIS NO ENSINO MÉDIO}

Este estudo de caso realizou-se em uma escola estadual na periferia de Maceió, em Alagoas, com estudantes na faixa etária de 15 a 29 anos, concluintes do Ensino Médio. O objetivo foi o de analisar as representações dos jovens sobre aspectos da cultura em Alagoas, sobre identidades juvenis e sobre a experiência escolar. O estudo baseou-se em três instrumentos metodológicos: questionários, grupos de discussão e entrevistas semiestruturadas individuais. A questão central do questionário aplicado aos sujeitos da pesquisa era a seguinte: "Se um alienígena chegasse a Terra e pedisse para que você apresentasse a ele a cultura de Alagoas, o que você diria?". O objetivo era investigar que referências vêm à mente dos jovens quando pensam nas referências culturais alagoanas e quais elementos eles expressariam como significativo sobre sua cultura.

As respostas dos depoentes apontaram para diferentes direções. Alguns focalizaram as representações dominantes sobre a "cultura alagoana", lembrando expressões culturais tradicionais, como o rótulo de "Paraíso das Águas", comumente associado ao estado por ter praias consideradas belas. Assim, para alguns jovens, a cultura é representada como produto destinado ao turismo, sendo que alguns afirmam que deveria haver mais "investimento" na cultura com o objetivo de agradar aos turistas.

Outros jovens explicaram que não estariam preparados para responder a essas questões, indicando a necessidade de pesquisar sobre o assunto, como se suas próprias referências culturais sobre o lugar onde vivem fossem algo que o sujeito precisa estudar para ter acesso. Outro ponto significativo foi a ocorrência de fatores como a violência e a má administração sendo evocadas pelos jovens como algo a ser apresentado como parte da sua cultura. Alguns textos tinham um tom de protesto, em relação à administração pública, à violência e à qualidade da educação em Alagoas.

Alguns estudantes apresentam o sentimento de discriminação vivenciado em relação aos outros estados do Brasil e, ainda, a necessidade de reagir, de lutar contra esse tipo de representação. Nesse sentido, alguns jovens apresentam questionamentos aos modos como os aspectos culturais alagoanos são compreendidos, reivindicando um maior sentimento de pertencimento. 
Várias repostas indicaram que os jovens percebem que a escola poderia contribuir também para o conhecimento das referências culturais locais. Identifica-se ainda necessidade de valorização da produção cultural alagoana e a percepção de que a escola poderia propiciar maior reconhecimento dos modos de expressão juvenis, reinventados, apropriados a partir de referências culturais que historicamente seriam de outros lugares, como o rap, mencionado por um dos jovens como sendo "sua" cultura: "Minha cultura é forte, é quase uma "não cultura" (Arnaldo, 20 anos, noturno).

Em algumas respostas do questionário, os alunos expressam a queixa de que a escola deveria apresentar no currículo os conhecimentos sobre a cultura em Alagoas, defendendo a falta de espaço para o tema no ambiente escolar tem contribuído para o distanciamento dos jovens alagoanos da cultura do seu estado. Os jovens depoentes percebem que a escola poderia contribuir para o conhecimento de aspectos da cultura local, mas que não tem trabalhado essa dimensão na sua formação. Identificamos, desse modo, a vontade de discutir questões específicas do seu estado, de sua cidade, de seu bairro, dentro do ambiente escolar. Podemos perceber nos depoimentos que esses jovens acreditam que o conhecimento da história e dos bens culturais do local onde vivem, contribuiria para a construção de uma estrutura de informações e de autoestima, ajudando-os a exercer sua autonomia enquanto jovens globalizados, mas que conhecem sua herança cultural e podem distinguir suas raízes em meio à massificação e mundialização da cultura, como salientou Pais (2003).

Ao questioná-los se a escola deveria trabalhar mais assuntos relacionados aos aspectos culturais de Alagoas, os participantes responderam que isso seria interessante, mesmo que em atividades extraclasses como gincanas ou oficinas. Concordamos com Dayrell (1996, p. 156) quando diz que "a aprendizagem implica, assim, estabelecer um diálogo entre o conhecimento a ser ensinado e a cultura de origem do aluno". Dessa maneira, é revelador o fato de os jovens mostrarem interesse sobre esse tema, mesmo na situação de carência de conhecimentos sobre o estado e a queixa recorrente da ausência da matéria "História de Alagoas".

Diante dos textos dos sujeitos desta pesquisa, percebemos que há a necessidade de espaço no ambiente escolar para aspectos culturais de Alagoas, com o objetivo de fortalecer sua autoestima, porque são representados de forma negativa nos meios de comunicação de massa. Geralmente Alagoas é retratada como sinônimo de subdesenvolvimento, corrupção e violência.

Trabalhar com jovens - com sua multiplicidade cultural - requer um conhecimento de suas expectativas para que a escola possa ser um ambiente de pertencimento desses sujeitos e consiga explorar toda sua potencialidade, não somente em sua função pedagógica, mas também como local de sociabilidade, de afetos e de desenvolvimento de seres humanos conscientes de si mesmos e de sua relação com os outros. Por esse motivo, considero interessante investigar como esse jovem que está na escola pensa na sua cultura e como esse sujeito vê a relação da sua identidade cultural com a sua experiência escolar.

Posteriormente os jovens participaram dos grupos de discussão, para os quais foi usado um procedimento metodológico inspirado na metodologia utilizada por Weller (2006). Foram formados dois grupos, um com oito participantes do turno diurno e outro com onze participantes do turno noturno. Realizamos dois encontros com cada um dos grupos. Na ocasião também foi 
feito um levantamento do "Perfil dos Integrantes do Grupo de Discussão" com o objetivo de obter algumas informações sobre os participantes, especificamente em relação à família, estudos e lazer.

Tendo em vista que "[...] a representação, compreendida como um processo cultural, estabelece identidades individuais e coletivas e os sistemas simbólicos nos quais ela se baseia" (WOODWARD apud SILVA, 2005, p. 18), nossa intenção era captar as representações das identidades individuais e coletivas expressas pelos sujeitos, questionando aos participantes dos grupos de discussão o que representava para eles "ser um jovem alagoano". Obtivemos duas categorias de respostas: as que enfatizam as questões de "escolha" e as que ressaltaram o "mercado de trabalho" e a "falta de oportunidades".

As discussões do turno diurno enfatizaram as questões de "escolha", os jovens afirmaram que é necessário se afastar de alguns grupos juvenis, para evitar determinados "modos de vida" que possam prejudicar os objetivos em relação ao futuro. Para uma das jovens, esse "isolamento" impede a vivência de experiências tidas como típicas da condição juvenil. A falta de condições para a criação e experimentação de espaços intersticiais traz como consequência "[...] a impossibilidade de construção do mundo a partir dos valores que a juventude considera como sendo seus." (CARRANO; MARTINS, 2011, p. 53)

De fato, algo que chamou a atenção quando nas respostas sobre opções de lazer desses jovens, todos os participantes do turno diurno afirmaram que seu lazer se resumia à escola e à igreja, que ficavam muito em casa e usavam a internet. Percebemos indícios de que não há para esses jovens outras opções de espaços de socialização para a vivência de momentos de jogos, de expressões culturais e lúdicos aos quais os jovens geralmente são associados. Os momentos em que essas experiências acontecem, são em geral vividos na escola. O que corrobora com a afirmação de Dayrell (2007, p. 1121), quando ressalta a importância da escola como espaço de trocas subjetivas, onde "[...] no caso dos jovens pobres, a sociabilidade ganha uma maior dimensão, à medida que a ausência de equipamentos públicos e de lazer nos bairros desloca para a escola muitas das expectativas de produção de relações entre os pares".

A realidade desses jovens é influenciada pela insegurança de um bairro no qual a violência vêm crescendo, onde vários conjuntos originaram-se de favelas, em que os barracos de lona deram lugar às casas construídas pelo poder público e distribuídas às famílias que hoje lá residem, um bairro onde os espaços de lazer são raros e geralmente são campos de futebol de chão batido. Esses indícios, que são também identificados em outros estudos nos levam a afirmar que se faz necessário o investimento em políticas que garantam a esses jovens o acesso a equipamentos de cultura e de lazer; que garantam segurança para que se possa transitar livremente em qualquer horário, "[...] transformando o espaço público em espaços de encontro, de estímulo e de ampliação das potencialidades humanas dos jovens, e possibilitando, de fato, uma cidadania juvenil." (DAYRELL, 2007, p. 1125). Sem essas condições, os jovens continuam tendo a escola como, senão o único, um dos poucos espaços de sociabilidade juvenil possível.

Ao serem questionados sobre o que é "ser jovem alagoano", os jovens, no grupo noturno, mencionaram o "mercado de trabalho" e a "falta de oportunidades" na maioria das respostas. A justiça social e a oportunidades para o pleno exercício da cidadania, ambas relacionadas à 
qualidade da educação destinada a esses jovens aparecem como questões essenciais para a vivência da condição juvenil.

Para muitos dos sujeitos dessa pesquisa os projetos de futuro de entrelaçam com a necessidade de sobrevivência no presente, o que aproxima do que dizem Sposito (2005) e Dayrell (2007) sobre a grande parcela de jovens para os quais a condição juvenil só é vivenciada porque trabalham. Nesse caso, escola e trabalho são realidades que os jovens precisam administrar, para garantir o mínimo de recursos para o lazer, o namoro, o consumo. "Nesse sentido, o mundo do trabalho aparece como uma mediação efetiva e simbólica na experimentação da condição juvenil, podendo-se afirmar que 'o trabalho também faz a juventude'" (DAYRELL, 2007, p. 1109).

Essa relação com o mercado de trabalho também aparece fortemente no grupo noturno, nas discussões que sobre autoestima e sobre a contribuição da escola para a formação da identidade deles como alagoanos. Uma das jovens expressou o seguinte:

Eu estudei no ProJovem Urbano. Pra mim... eu não esqueço! Pra mim o ProJovem foi uma coisa muito boa, participativa. (...) Os cursos que tive! Tudo ótimo! (...) Porque o ProJovem, ele oferece! Ele quer que você cresça! (...) Com certificado, tudo certinho! E quando você comenta que você tem certificado do ProJovem Urbano, as pessoas se agradam. Acham certo sabe? [Isolda, 23 anos, noturno]

Percebemos que a relação que a jovem tinha visto entre a sua experiência no ProJovem e a construção da sua identidade, na verdade era o sentimento de satisfação em reconhecer o sentido dos estudos naquele curso profissionalizante. Para ela o curso foi tão gratificante e repleto de significados que a marcou, a ponto de ser mencionado no momento da discussão. Identificamos que a maioria dos jovens não tem vivenciado esses espaços significativos de formação no Ensino Médio pois precisam se sentir valorizados em relação aos conhecimentos propiciados em sua experiência escolar. Para compreender a mobilização dos estudantes em relação aos estudos, torna-se necessário identificar como os processos de ensinar na escola se articulam ou não com o reconhecimento dos modos de aprender, de expressão dos jovens (REIS, 2012).

Aprender e compreender, seja na escola ou em outros lugares, precisa ter um sentido "existencial" para os jovens, pois, além da utilidade para a vida profissional, a percepção desse sentido agrega valores identitários que refletem em sua autoestima, especialmente nos meios populares, em razão das difíceis condições de sobrevivência. Isso implica estabelecer cada vez mais relações entre sua condição juvenil e o estatuto de aluno, tendo de definir a utilidade social dos seus estudos, o sentido das aprendizagens e, principalmente, seu projeto de futuro. (DAYRELL, 2007, p. 1120). Os estudos devem possibilitar aos jovens a possibilidade de mobilização em relação ao aprender na escola articular a experiência escolar às suas outras experiências significativas.

Por outro lado, os jovens também expressaram a frustração em perceber que o conhecimento do aluno não está em primeiro lugar quando se trata do sistema educacional público de Alagoas, que, como outros estados do Brasil, sofre com a falta de professores e com o atrelamento às metas quantitativas de desempenho estabelecidas nacionais e internacionalmente pelas avaliações externas em relação à escolarização.

A precarização do ensino é explicitada por esses jovens quando expressam que em determinadas áreas do conhecimento os professores chegam à escola na metade do ano letivo, 
para assumir disciplinas que antes estavam sem professor, precisam cumprir o calendário e fechar as notas no mesmo prazo das disciplinas que foram lecionadas desde o início do ano letivo. Os professores fazem o que podem para se adequar ao sistema, porém, além dos prejuízos nos conteúdos aos quais os estudantes deveriam ter acesso, isso gera a revolta dos jovens por perceberem que sua educação escolar é tratada de forma meramente quantitativa.

Nesse aspecto, Dayrell afirma que "a relação dos jovens pobres com a escola expressa uma nova forma de desigualdade social, que implica o esgotamento das possibilidades de mobilidade social para grandes parcelas da população e novas formas de dominação" (2007, p. 1122). O que podemos perceber é que alguns jovens já desistiram de obter qualquer benefício através da escola e seu único objetivo agora é o certificado do Ensino Médio e o encerramento dessa etapa da vida.

Além das críticas ao sistema - que por si só já contribui negativamente - outra queixa expressa pelos sujeitos desta pesquisa, diz respeito à postura de alguns professores que, segundo os jovens, não demonstram interesse em incentivá-los em sua experiência escolar. Os participantes dos dois grupos - diurno e noturno - queixaram-se do tratamento que recebem de dos professores, que, segundo eles, não os estimulam a melhorar. Ao invés disso, contribuem para a diminuição do interesse dos jovens pelo estudo e prejudicam a autoestima dos mesmos.

A possibilidade de falta de respeito e de descaso, segundo o relato do aluno, reforça o argumento de alguns pesquisadores de que é preciso repensar a escola em sua relação com as juventudes, pois "se antes a autoridade do professor era legitimada pelo papel que ocupava, constituindo-se no principal ator nas visões clássicas de socialização, atualmente é o professor que precisa construir sua própria legitimidade entre os jovens". (DAYRELL, 2007, p. 1121). Observa-se também uma tendência em atribuir aos jovens a responsabilidade pelo seu sucesso ou fracasso, como reflexo disso, percebe-se por parte de alguns jovens uma tendência em assumir para si essa responsabilidade. Diante das deficiências do sistema educacional, vemos alguns jovens lutando com o que podem - se possível, buscando condições fora da escola média - para alcançar seus objetivos, enquanto são assombrados pela possibilidade de insucesso nos estudos e, consequentemente, na vida. Sobre esse aspecto, Dayrell afirma que

A sociedade joga sobre o jovem a responsabilidade de ser mestre de si mesmo. Mas, no contexto de uma sociedade desigual, além deles se verem privados da materialidade do trabalho, do acesso às condições materiais de vivenciarem a sua condição juvenil, defrontam-se com a desigualdade no acesso aos recursos para a sua subjetivação. A escola, que poderia ser um dos espaços para esse acesso, não o faz. Ao contrário, gera a produção do fracasso escolar e pessoal. Como lembra Dubet (2006), o dominado é convidado a ser o mestre da sua identidade e de sua experiência social, ao mesmo tempo que é posto em situação de não poder realizar este projeto. (2007, p. 1122-1123)

Não se pode negar a influência do pensamento inerente à sociedade neoliberal, onde o indivíduo é incentivado a desenvolver todas as suas capacidades e é tido como o único responsável pelo seu sucesso ou fracasso. Percebe-se que diante de todas as dificuldades, que são particularmente agravadas nos cursos noturnos, surge a tendência em assumir uma postura quase autodidata para suprir as carências de um sistema público de ensino deficiente. Observa-se que os 
jovens e as jovens que conseguem encontrar caminhos para a apropriação de conhecimentos gratificantes e realmente significativos o fazem em grande parte utilizando seus próprios esforços e "garimpando" onde podem as mais variadas fontes de saber.

A variedade das formas de pensar e das posturas dos jovens durante a realização dos grupos de discussão fez necessário o aprofundamento do diálogo com alguns dos sujeitos desta pesquisa. Foram selecionados três jovens, entre os participantes dos grupos de discussão. Para alcançar esse objetivo optamos pela entrevista semiestruturada, utilizando um roteiro com questões norteadoras, mas que não seguem obrigatoriamente uma ordem e uma formulação fixa, sendo utilizadas de acordo com o desenvolvimento das respostas, uma vez que este tipo de entrevista colabora muito na investigação dos aspectos afetivos e valorativos dos sujeitos que determinam significados pessoais de suas atitudes e comportamentos. Além disso, as respostas espontâneas dos entrevistados e a maior liberdade que estes têm fez surgir questões inesperadas que foram de grande utilidade na pesquisa.

Um dos aspectos observados nos relatos das histórias de vida dos sujeitos dessa pesquisa foi a importância das questões familiares, o que nos faz perceber que essa relação com a família influencia todos os aspectos das trajetórias de vida dos jovens. Em seus argumentos eles explicitam a relação com a família, juntamente com as questões de espiritualidade, fornecem uma estrutura emocional importante para a superação de vários dos desafios que os jovens precisam enfrentar. Durante toda a pesquisa, a maioria dos jovens que apresentaram posturas mais esclarecidas, segurança e desenvoltura discursiva, tanto nos grupos de discussão como nas entrevistas, mencionaram a formação espiritual/religiosa como uma dimensão importante de sua identidade. Isso nos faz considerar que essa base emocional, afetiva, religiosa, familiar possibilita a segurança percebida nos posicionamentos desses jovens diante dos questionamentos lançados.

O aspecto lúdico também foi apontado como uma característica do "ser jovem". Para um dos entrevistados, o "poder brincar" é algo que, de certa forma ainda é permitido ao jovem, como se o "ser adulto" esgotasse as possibilidades de viver o lado lúdico da vida. Outro aspecto apontado por ele é a possibilidade de "sonhar", no sentido de criar expectativas, de projetar o futuro, como se o único momento para ter sonhos e objetivos fosse à juventude e ao sair dessa "fase" o indivíduo perdesse a capacidade, ou talvez a possibilidade de criar maiores expectativas para o futuro.

Em relação aos aspectos negativos da condição juvenil, alguns jovens apontam a questão da "inexperiência" e das influências que levam o jovem a fazer escolhas prejudiciais à sua vida, como, por exemplo, o envolvimento com drogas. Para alguns sujeitos desta pesquisa, os jovens não costumam ouvir as pessoas adultas e não buscam aprender com os conselhos e os exemplos de vida dos pais, dos professores ou de pessoas com mais experiência, para ele, os jovens "se perdem" por ouvirem somente os outros jovens. Nesse sentido alguns jovens têm a consciência de que para "não ser" é preciso, muitas vezes optar pelo isolamento. Porém, "esta diferença, paradoxalmente, só pode ser afirmada e vivida como tal, ao supor uma certa igualdade, uma certa reciprocidade" (SPOSITO, 2005, p. 99). Para um dos jovens, o isolamento é uma estratégia de manutenção da amizade com aqueles com os quais ele, mesmo consciente de suas diferenças, faz questão de cultivar as relações e afirmar semelhanças. Para outra jovem, esse "isolamento" impede a vivência de experiências tidas como típicas da condição juvenil. 
A menção de um dos jovens ao fato de ser estudante, como sendo algo que faz dele um jovem, chama a atenção e reforça a ideia de que a experiência escolar constitui um referencial importante para a vivência da condição juvenil.

O que me faz jovem ainda também é: 30 ano; terminar o ensino médio; ainda não tenho emprego... me sinto um jovem... aquele jovem.. não desmotivado, mas que ainda pensa em algumas coisas que não me deixam ser adulto. Tenho alguns pensamentos de adulto mas me contento em ser jovem. (Arnaldo, 20 anos, noturno)

Por outro lado, um dos entrevistados, afirma não se sentir um jovem, uma vez que, segundo ele, as dificuldades enfrentadas do decorrer de sua história o fizeram amadurecer, a ponto de ele considerar que as "coisas de jovem" já não despertam seu interesse.

Sobre os conhecimentos obtidos em diferentes espaços sociais, um dos entrevistados possui atividades extraescolares, ligadas ao movimento GLBT, do qual faz parte. Por ser travesti, já passou por diversas experiências negativas no ambiente escolar. Segundo ele, a rejeição maior parte dos professores. Durante sua entrevista, Val demonstrou sentir falta do apoio dos professores, no sentido de contribuir para a disseminação de informações referentes à cultura na qual ele se inseriu. Durante a entrevista, o jovem manifesta a percepção de que há algo a ser feito:

Eu faria mais projetos de conscientização. Porque eu já sofri muito preconceito. Uma professora, umas três semanas seguidas, me chamou pelo meu nome de registro e eu já tinha pedido pra ela me chamar pelo meu nome social. Mas ela insistiu em me chamar pelo nome de registro na chamada. Então eu faria mais projetos pra ensinar os professores como trata... porque os alunos se enturmam mais fácil. Mas os professores precisam ser mais conscientizados. Porque é assim, todo mundo tem seus direitos só que, como você é considerada "normal" pra sociedade você recebe seus direitos. $\mathrm{E}$ eu, pra receber os meus, tenho que lutar. (Val, 24 anos, noturno)

É preciso compreender os jovens estudantes na sua diferença, enquanto indivíduos que possuem uma historicidade, com visões de mundo, escalas de valores, sentimentos, emoções, desejos, projetos, com lógicas de comportamentos e hábitos que lhe são próprios (DAYRELL, 1996, p. 140). Essa outra perspectiva implica em superar a visão homogeneizante e estereotipada da noção de aluno, dando-Ihe outro significado.

De acordo com as entrevistas, bem como nas discussões nos grupos, percebemos que a relação professor-aluno, em geral, apresenta-se fria, distante, praticamente repulsiva, devido a um modelo pedagógico que sufoca qualquer tentativa de relação mais humanizada. Sobre esse assunto Dayrell faz uma reflexão bastante significativa:

Os professores, na sua maioria, presos que estão a esta forma de lidar com os conteúdos, deixam de se colocar com expressão de uma geração adulta, portadora de um mundo de valores, regras, projetos e utopias a ser proposto aos alunos. Deixam de contribuir no processo de formação mais amplo, como interlocutores desses alunos, diante das suas crises, dúvidas, perplexidades geradas pela vida cotidiana. (1996, p. 140) 
Concordamos com o autor quanto à necessidade de se repensar a postura dos professores e de toda a instituição escolar no sentido de se conceder espaço a um diálogo com os jovens estudantes, criando possibilidades de compreensão de seus questionamentos, suas crises, suas expectativas, enfim, suas identidades. Isso contribuiria para um reconhecimento, por parte dos jovens, da escola como um ambiente de pertencimento, onde os jovens podem buscar não somente os conteúdos repassados pelas matérias estudadas, mas também um suporte para fragilidades, onde os professores seriam fonte de um conhecimento de vida e para a vida.

Por outro lado, mesmo identificando a consciência, por parte dos jovens, de que a escola está longe de atender suas expectativas e reais necessidades, é possível identificar também demonstrações de gratidão e reconhecimento da importância da escola para seu desenvolvimento pessoal. Consideramos significativa a expressão apresentada por alguns dos jovens participantes desta pesquisa: a tendência em assumir uma postura quase autodidata para suprir as carências de um sistema público de ensino deficiente. Observa-se que os jovens alunos que conseguem encontrar a via para aquisição de um conhecimento gratificante e realmente significativa o fazem utilizando seus próprios esforços e "garimpando" onde podem as mais variadas fontes de saber. Carrano e Martins (2011, p. 45) defendem que

[...] uma das mais importantes tarefas das instituições, hoje, seria a de contribuir para que os jovens pudessem realizar escolhas conscientes sobre suas trajetórias pessoais e constituir os seus próprios acervos de valores e conhecimentos que já não mais são impostos como heranças familiares ou institucionais.

Porém, o que se observa é que as escolas, muitas vezes, com tantas "cobranças e demandas externas", seus modos de organização do tempo e espaço pouco maleáveis, dentre outros aspectos, têm assumido uma posição oposta. De acordo com Sposito "a escola conta com mecanismos de silenciamentos que promovem a invisibilidade das práticas que não se encaixam nos cotidianos escolares institucionalizados e pouco abertos para as expressividades das culturas juvenis. Nesse contexto, o jovem é homogeneizado na condição de aluno que necessita responder positivamente aos padrões do "ser estudante" que a instituição almeja." (SPOSITO apud CARRANO; MARTINS, 2011, p. 45)

É importante refletir que "[...] a escola, em especial a de Ensino Médio, constitui-se em instituição privilegiada de promoção de suportes para que os jovens elaborem seus projetos pessoais e profissionais para a vida adulta" (CARRANO; MARTINS, 2011, p. 44), visualizando essa via de mão dupla entre aquilo que herdam do denominado "mundo adulto" e a capacidade do jovem de construir seus próprios repertórios culturais.

\section{CONSIDERAÇÕES FINAIS}

Reconhecemos que ser jovem e estudante do ensino médio implica em papéis sociais diferenciados, mas que se entrecruzam e se misturam em todo momento. Na escola e na sala de aula, um jovem não deixa para traz seus modos de se expressar como jovens, apreendidos em outros espaços sociais, do mesmo modo, esses trazem consigo os desafios de desvendar as lógicas específicas do espaço escolar e precisam aprender, na escola, as exigências construídas 
especificamente sobre os seus modos se relacionar com os outros e de aprender a valorizar-se nesse espaço.

Portanto, coexistem essas dimensões que podem estar bem articuladas, obscurecidas, em tensão ou em disputa. Certamente, algumas situações pressupõem que uma identidade se sobreponha a outra, mas faz parte desse processo identitário, no qual os modos de se reconhecer e de ser reconhecidos pelos outros, de classificação de si, dos outros e do mundo estão em um constante processo de negociação e reinvenção. No entanto, quando jovens não se sentem valorizados, reconhecidos em suas potencialidades, quando não podem se expressar, essa experiência escolar pode ser considerada como algo de difícil articulação positiva em relação ao seu processo identitário. A experiência escolar pode ser identificada como angustiante, pode ser em grande parte ignorada em relação aos outros espaços vivenciados ou até mesmo ser tratada com hostilidade e violência.

Os debates acerca do tema "juventudes e escola" evidenciam a necessidade de se refletir sobre as mudanças ocorridas na sociedade e o que precisa ser feito para que a escola corresponda melhor às exigências de jovens que transitam entre dois mundos nos quais coexistem como jovens e como estudantes, mas que muitas vezes parecem totalmente separados: a escola e fora dela. Não há uma juventude única, homogênea, mas sim múltiplas, plurais e além disso, variáveis, mutantes e tantos outros termos que expressam a pluralidade de realidades possíveis nessa fase da vida. Na verdade, são possibilidades de ser jovem, inseridas em realidades sociais e culturais que delineiam a condição juvenil. E cada sujeito experimenta essa condição do seu modo, tornando cada um dos atores sociais um amplo objeto de estudo. A condição juvenil se apresenta com um prisma, onde a condição humana se refrata em múltiplas realidades.

Permeando a condição juvenil encontra-se a escola, envolvida em vários dos dilemas e soluções inerentes à vida dos jovens estudantes. Ela - a escola - fornece tantos outros questionamentos: a insatisfação dos jovens por não serem reconhecidos em seus esforços nos estudos, como também por não ser reconhecidos por seus modos de expressão, suas culturas juvenis, seus engajamentos políticos nos espaços onde atuam; a desarticulação entre alunos e professores que tanto prejudica o diálogo e a apreensão dos conhecimentos; as precariedades do sistema como um todo, que obriga alunos e professores a se adequarem ao que está posto, quando não sobra outra alternativa; enfim os tão conhecidos e discutidos problemas, gerados por condições políticas, sociais, culturais, que alimentam a relação de "amor e ódio" entre a escola e os jovens que lhe dão vida.

Identificamos diversos aspectos da condição juvenil e sua relação com a experiência escolar. Entre os mais significativos, as diferenças entre as realidades dos turnos diurno e noturno. Para o primeiro grupo, a condição juvenil está ligada às expectativas quanto ao futuro; à preocupação com o ENEM; ao cuidado com as relações pessoais, em saber com quem se envolver para não prejudicar sua trajetória de vida. Para o segundo grupo, a condição juvenil é permeada pelas exigências do mercado de trabalho; pela conciliação entre trabalho e estudo; pela precariedade do ensino. Em ambos os casos é presente a busca por um conhecimento realmente significativo, que gere um reconhecimento gratificante de que todo o seu esforço faça sentido, para que com todas as dificuldades, valha a pena estudar. 
Nesse contexto, a relação entre professores e alunos apresentou-se marcante nas discussões realizadas. É inegável, corroborando com os argumentos dos sujeitos pesquisados, a importância do professor, em seu papel de incentivador ou de repressor, de facilitador ou destruidor das possibilidades de sucesso dos jovens em sua trajetória escolar e até mesmo pessoal, uma vez que é preciso considerar o jovem estudante, além da condição de aluno, em sua dimensão humana total, como sujeito sociocultural, em sua diversidade de culturas e de identidades.

Procuramos registrar aspectos identitários ligados à subjetividade e à individualidade: a relação com a família, a religião e a relação com o saber; a condição de vivenciar sua sexualidade, perpassando cada uma dessas identidades, buscando mostrar aspectos diversos da condição juvenil que se delineiam de acordo com cada realidade expressada.

Diante dos resultados obtidos nesta pesquisa, e corroborando com o que diversos autores estudados apresentam, consideramos que o Ensino Médio representa uma "fase" da vida estudantil que precisa ser repensada, de acordo com a complexidade de nosso contexto social, cultural, político e econômico, por sujeitos marcados pela necessidade de serem reconhecidos em sua igualdade de direitos e pelo respeito as suas diferenças no modo de ser, de se expressar no mundo. Nesse aspecto, considerar as identidades juvenis, reconhecer seus modos de expressão, valorizar suas referências culturais, debater sobre os pré-conceitos construídos historicamente em relação a sua história - uma vez que esta retrata a experiência de vida de cada um dos jovens estudantes - é algo que enriquece o trabalho pedagógico, e fortalece a autoestima de jovens alunos e alunas. As análises desse estudo com os jovens estudantes revelam, portanto, a necessidade de se considerar as diversas identidades juvenis presentes do ambiente escolar, em favor do diálogo e valorização de seus modos de expressão e da contribuição significativa da experiência escolar para a sua construção identitária.

\section{REFERÊNCIAS BIBLIOGRÁFICAS}

1. ABRAMO, Helena, Wendel. Condição Juvenil no Brasil Contemporâneo. In: ABRAMO, H. W.; BRANCO, P. P. M. (Orgs.). Retratos da Juventude Brasileira: análises de uma pesquisa nacional. São Paulo: Instituto Cidadania/Fundação Perseu Abramo, 2005. p. 37-72.

2. CARRANO, Paulo Cesar Rodrigues; MARTINS, Carlos Henrique dos Santos. A escola diante das culturas juvenis: reconhecer para dialogar. Educação, Santa Maria, v. 36, n. 1, p. 43-56, jan./abr. 2011.

3. DAYRELL, Juarez. A escola faz as juventudes? Reflexões em torno da socialização juvenil. Educ. Soc., Campinas, vol. 28, n. 100 - Especial, p. 1105-1128, out. 2007.

$4 . \quad$ A A escola como espaço sócio-cultural. In: DAYRELL, Juarez. (Org.). Múltiplos olhares sobre educação e cultura. Belo Horizonte: UFMG, 1996. p. 136-178.

5. DUBAR, Claude. A crise das identidades: a interpretação de uma mutação. São Paulo: Edusp, 2009.

6. HALL, Stuart. A centralidade da cultura: notas sobre as revoluções de nosso tempo. Educação \& Realidade, Porto Alegre, v. 22, n. 2, p. 15-46, jul/dez, 1997.

7. A identidade cultural na pós-modernidade. Rio de Janeiro: DP\&A, 2011. 
8. PAIS, José Machado. Culturas juvenis. Lisboa, 2003.

9. REIS, Rosemeire. Experiência escolar de jovens/alunos do ensino médio: os sentidos atribuídos à escola e aos estudos. Educação e Pesquisa, São Paulo, v. 38, n. 03, p. 637-652, jul./set. 2012

10. SILVA, Tomaz Tadeu da. Identidade e diferença: a perspectiva dos estudos culturais. Petrópolis: Vozes, 2005.

11. SPOSITO, Marília Pontes. Indagações sobre as relações entre juventude e a escola no Brasil. Revista de Estudios sobre Juventud, México, ano 9, n. 22, p. 201-227, jan/jun. 2005.

12. WELLER, Wivian. Grupos de discussão na pesquisa com adolescentes e jovens: aportes teóricometodológicos e análise de uma experiência com o método. Educação e Pesquisa, São Paulo, v.32, n.2, p. 241-260, maio/ago. 2006.

13. ZALLUAR, Aluar. Gangues, galeras e quadrilhas: globalização, juventude e violência. In: Vianna, H. (Org.). Galeras cariocas. Rio de Janeiro: UFRJ, 2003. 